\title{
Intraoperative radiation therapy (IORT) in pancreatic cancer
}

\author{
Robert Krempien ${ }^{1 *}$ (D) and Falk Roeder ${ }^{2,3}$
}

\begin{abstract}
Despite the important improvements made in the fields of surgery, chemotherapy and radiation therapy, pancreatic cancer remains one of the most lethal malignancies. Improved outcomes with novel chemotherapy regimes led again to increased attention on the role of localized radiotherapy, since local tumor progression causes significant morbidity and mortality in patients. Even after resection local failure rates are as high as $50-80 \%$. The immediate proximity to critical structures (bone marrow, spinal cord, kidneys, liver, and intestine) limits the dose of radiation that can be administered to the tumor bed with conventional external beam radiation therapy (EBRT). The intraoperative radiotherapy (IORT) appears to be an ideal therapeutic strategy for this disease, having the advantage of enabling the delivery of high doses of radiation to areas that are at risk for microscopic disease, saving critical organs and reducing the possibility of inducing radiotoxicity. This technique allows a theoretical increase in the radiation therapeutic index to tumor compared to the adjacent organs at risk (OAR). The aim of this review is to update and comment on IORT in the multidisciplinary management of pancreatic cancer.
\end{abstract}

\section{Background}

Pancreatic cancer is the fourth commonest cause of death from cancer in men and women [1,2]. Surgical therapy currently offers the only potential monomodal cure for pancreatic adenocarcinoma [3]. However, only a few patients present with tumors that are amenable to resection, and even after resection of localized cancers, long-term survival is rare. At presentation, only $10-20 \%$ of patients with pancreatic adenocarcinoma have potentially resectable cancers, $40 \%$ have locally advanced unresectable tumors, and $40 \%$ have metastatic disease. Adenocarcinoma of the pancreas has a 5-year survival rate of only $4 \%$ [2]. In spite of the progress in surgical treatment, resulting in increased resection rates and a decrease in treatment-related morbidity and mortality, resection has failed to improve long-term survival [3]. By histological evaluation $<15 \%$ of the patients undergoing R0 resection have a $\mathrm{pNO}$ status, $>50 \%$ suffer from lymphangiosis carcinomatosa, and $>50 \%$ suffer from extrapancreatic nerve plexus infiltration $[4,5]$. Combined modality treatment approaches using chemotherapy or

\footnotetext{
* Correspondence: Robert.krempien@helios-kliniken.de

'Department of Radiation Oncology, Helios Clinic Berlin-Buch,

Schwanebecker Chaussee 50, Berlin-Buch, 13125 Berlin, Germany

Full list of author information is available at the end of the article
}

chemoradiation in addition to surgery are the mainstay in treatment of pancreatic cancer [4-8].

\section{Achievements of surgery}

Although surgery offers a low cure rate, it is also the only chance for cure. Regarding long-term survival after R0 resection, only $3-16 \%$ of the patients from selected series survived 5 years or more. Locoregional recurrence and/or metastatic disease develop in the majority of patients who undergo pancreatic resection. Relapse occurs within 9-15 months after initial presentation and patients have median life expectancies of only 12-15 months without adjuvant therapy. The 5-year survival rate of patients with resected pancreatic adenocarcinoma is approximately $10 \%$ [3]. The statistics for the $80-90 \%$ of patients who present with locally advanced and metastatic pancreatic cancer are even more dismal. Rarely do such patients achieve a complete response to treatment; median survival is $5-10$ months and 5-year survival is near zero [6].

The cardinal rule in improving the prognosis in patients with pancreatic cancer proved to be complete tumor removal in patients undergoing oncological resection [3, 4]. In most recent published prospective trials, $\mathrm{R} 0$ resection results in an increase of survival in comparison with patients with a residual tumor $[7,8]$. However, R0 resection fails to improve long-term survival 
[4]. More than $95 \%$ of the patients undergoing surgical resection are at an advanced stage of cancer. Potentially curative resection is hampered by a failure to include remote cancer cell-positive tissues in the operative specimen, i.e. N2 lymph nodes, nerve plexus, and perivascular tissue $[9,10]$. Cancer recurrence after resection with curative intent is the consequence of cancer cell-positive tissues left behind. However, comparison of the survival times after standard and extended resection of pancreatic cancers indicated that no significant long-term survival benefit resulted from extended R0 resection [11, 12].

\section{Dissemination pattern of pancreatic cancer}

Using molecular biological methods like reverse transcriptase polymerase chain reaction (RT-PCR) or immunostaining, a new dimension of micrometastasis has been objectified. With the higher sensitivity of these molecular biological methods, up to $60 \%$ of lymph nodes previously seen as microscopically free of cancer showed micrometastasis by RT-PCR even in UICC stage I or II cancers $[5,13]$. Nerve plexus invasion outside of the pancreas has been observed in $43-72 \%$ of patients $[14,15]$. Further, careful histopathological evaluation of cancer dissemination has demonstrated that even in stage I and II cancers, lymph vessels surrounding the pancreas are cancer cell infiltrated in most of the cases $[5,15]$.

This knowledge about cancer cell dissemination early in the course of pancreatic cancer, including early stage cancers, explains why true R0 resection in pancreatic cancer is difficult to achieve, and explains the observed frequency of recurrence in $>95 \%$ of patients undergoing surgical resection with curative intent.

\section{Combined modality treatment}

Both distant and local/regional patterns of recurrence are common, and this suggests that most patients have occult metastatic or local/regional disease (or both) at the time of resection. According to several phase II or III trials, combined modality treatment approaches using chemotherapy or chemoradiation in addition to surgery can achieve improvement in locoregional control and survival $[7,8,16]$. Novel systemic treatment regimens like FOLFIRINOX and nab-paclitaxel have demonstrated improvements in prolonging survival in advanced cases, but long-term survival is still scarce $[17,18]$.

\section{Radiation therapy dose escalation}

Several trials could show that dose escalation in radiation therapy resulted in improved local control in combination with potentially curative resection [19-21]. The efficacy of external beam radiation therapy (EBRT) in pancreatic cancer is limited by the inability to deliver adequate doses of irradiation secondary to the dose tolerance limits of small bowel, spinal cord, stomach, kidney, and liver. Further, the use of combined modality approaches in pancreatic cancer is associated with increased gastrointestinal toxicity. Technical developments like Intraoperative Radiation Therapy (IORT) have the potential to significantly improve radiation therapy of pancreatic cancers by reducing normal tissue dose, and simultaneously allow for escalation of dose to further enhance locoregional control [21, 22].

\section{Intraoperative Radiation}

Intraoperative radiation therapy (IORT) techniques allow for the delivery of high doses of radiation therapy while excluding part or all of the nearby dose-limiting sensitive structures. Therefore, the effective radiation dose is increased and local tumor control potentially improved. This is pertinent in the case of pancreatic cancer because local failure rates are as high as $50-80 \%$ in patients with resected and locally advanced disease [10]. In pancreatic cancer, IORT has been offered for unresectable tumors to provide local tumor control and palliation of pain, and for resectable tumors in an effort to improve local control and survival after PD [21].

\section{Technique of IORT}

Intraoperative radiation therapy is defined as the application of a single fraction of high dose irradiation during a surgical procedure. The target volume is usually the tumor bed after gross total resection or the remaining gross residual disease if resection was not (completely) possible. IORT is typically used as a boost after preoperative or prior to postoperative EBRT. The use of IORT alone should be restricted to situations without a reasonable opportunity for EBRT (for example recurrence after prior irradiation). Technically, two major approaches are in use for IORT treatments of pancreatic cancer: electrons and HDR-brachytherapy [23, 24]. After surgical removal of the tumor, the target volume is defined by the radiation oncologist in correspondence with the treating surgeon (Figs. 1 and 2). An IORT boost offers several advantages compared to an EBRT boost: first of all, radiosensitive structures or organs at risk can be surgically moved out of the radiation field and therefore effectively spared from radiation exposure. Target volume definition takes place under visual control which minimizes a possible geographical miss. Safety margins can be kept to a minimum as no substantial intra- or interfractional movements have to be taken into account and finally overall treatment time is shortened. These advantages have to be weighed against some drawbacks: No final pathological assessment of margin status will usually be available for treatment stratification. Late toxicity might be increased at least theoretically due to the use of a high single dose. Three-dimensional treatment planning is not (yet) available, treatment documentation can be 


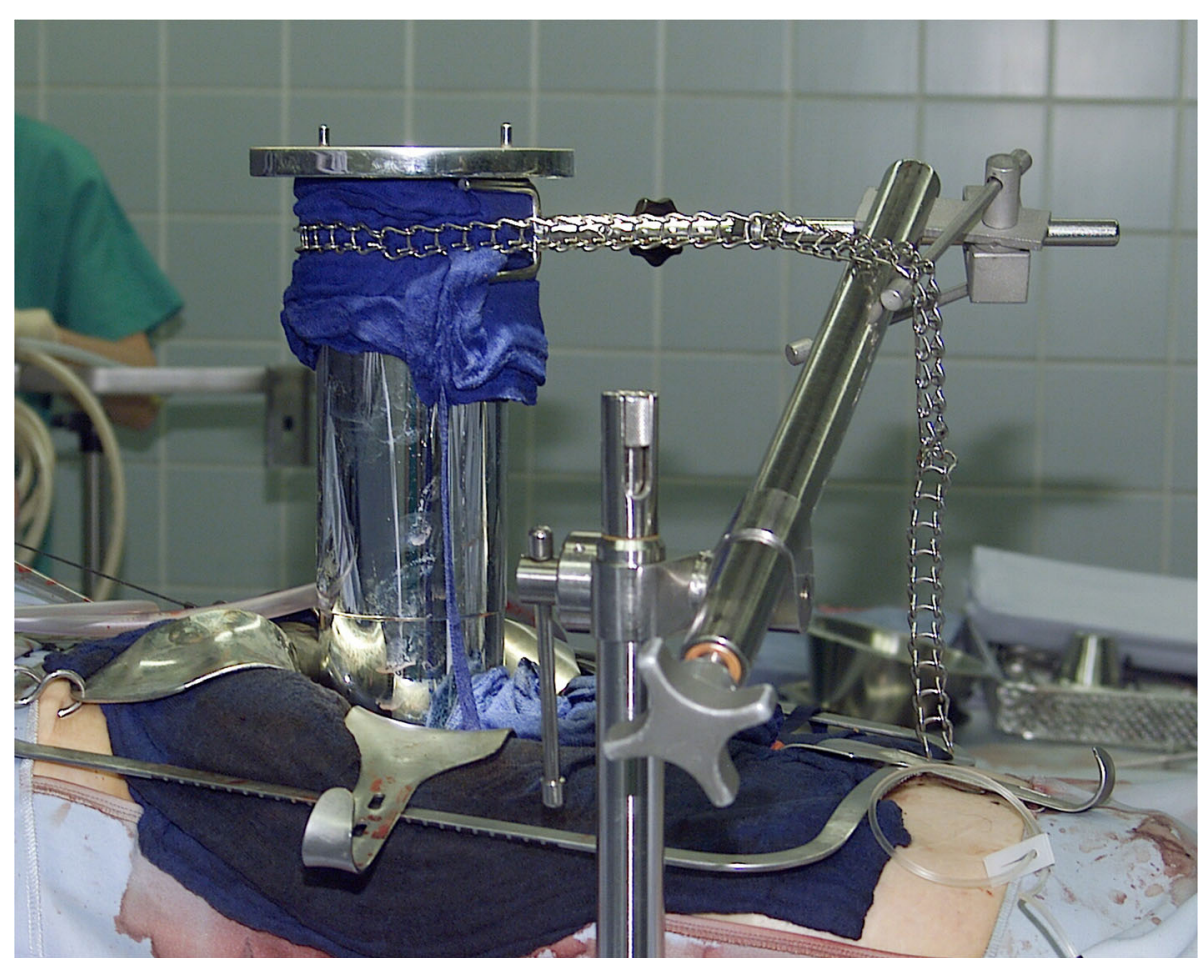

Fig. 1 Intraoperative radiation Therapy with electrons (IOERT). Placement of an intraoperative electron beam applicator in a patient with pancreatic cancer. An applicator of appropriate size is chosen, manually positioned and attached to the table. Applicators are made of steel or plastic to restrict the radiation field laterally and are usually available in different sizes, shapes and bevel angles. Prior to irradiation, the axis of the applicator has to be aligned properly with axis of the LINAC in a defined distance. The dose is usually prescribed to the $90 \%$ isodose

difficult and finally doing IORT is a major interdisciplinary effort and therefore only available at large centers [23].

Typically single doses of $10-20$ Gy are used. However, the conversion of high single doses into biologic equivalent doses in fractionated therapy is difficult. For example, a single dose of 15 Gy would be equivalent to 31-54 Gy in conventionally fractionated RT regarding tumor and late reacting tissue response using the linearquadratic model and assuming alpha/beta values of 3-10 $[18,19]$. However the linear quadratic model is not validated for high single doses and probably overestimates the equivalent fractionated dose [25, 26]. Further on there is growing evidence for a different tissue reaction to high single doses per se if a threshold of 8-10 Gy is exceeded [27]. Taken alternative models [26] and the clinical experience into account, it seems more reliable to assume an equivalent fractionated dose which is $2-3$ fold the IORT dose, while the tumor effect seems rather 2 fold and the late reacting tissue effect rather 3 -fold. This underlines the need for optimal sparing of organs at risk and the combination of IORT with EBRT whenever feasible.

\section{IORT in pancreatic cancer: The Beginning}

Initial studies were conducted at the University of Kyoto. In these early studies resection was followed by IORT doses of 25-30 Gy [28]. Nishimura et al. reported an improvement in survival and pain relief in a series of patients with advanced pancreatic cancers treated with IORT doses of 20-40 Gy compared with the control arm [29]. These studies prompted further investigations. Shipley et al. evaluated 20 Gy IORT in patients with unresectable disease in combination with EBRT. Median survival was 16.5 month with approximately $50 \%$ of patients achieving pain relief [30]. Roldan et al. retrospectively evaluated 159 patients treated between 1974 and 1985 with IORT in addition to postoperative EBRT. Local control was improved at both 1- and 2-year time points, though not overall survival [31].

\section{Safety of IORT in pancreatic cancer}

Importantly, the addition of IORT after surgery did not increase perioperative complication rates significantly. Although late complications have been reported after IORT for pancreatic cancer, all reports suggest that IORT may be delivered safely even in combination with surgical resection (Tables 1 and 2) [20]. Selection of radiation doses for IORT was influenced by seminal, preclinical canine experiments performed at the National Cancer Institute that provided an understanding of normal tissue tolerances, including surgically manipulated 


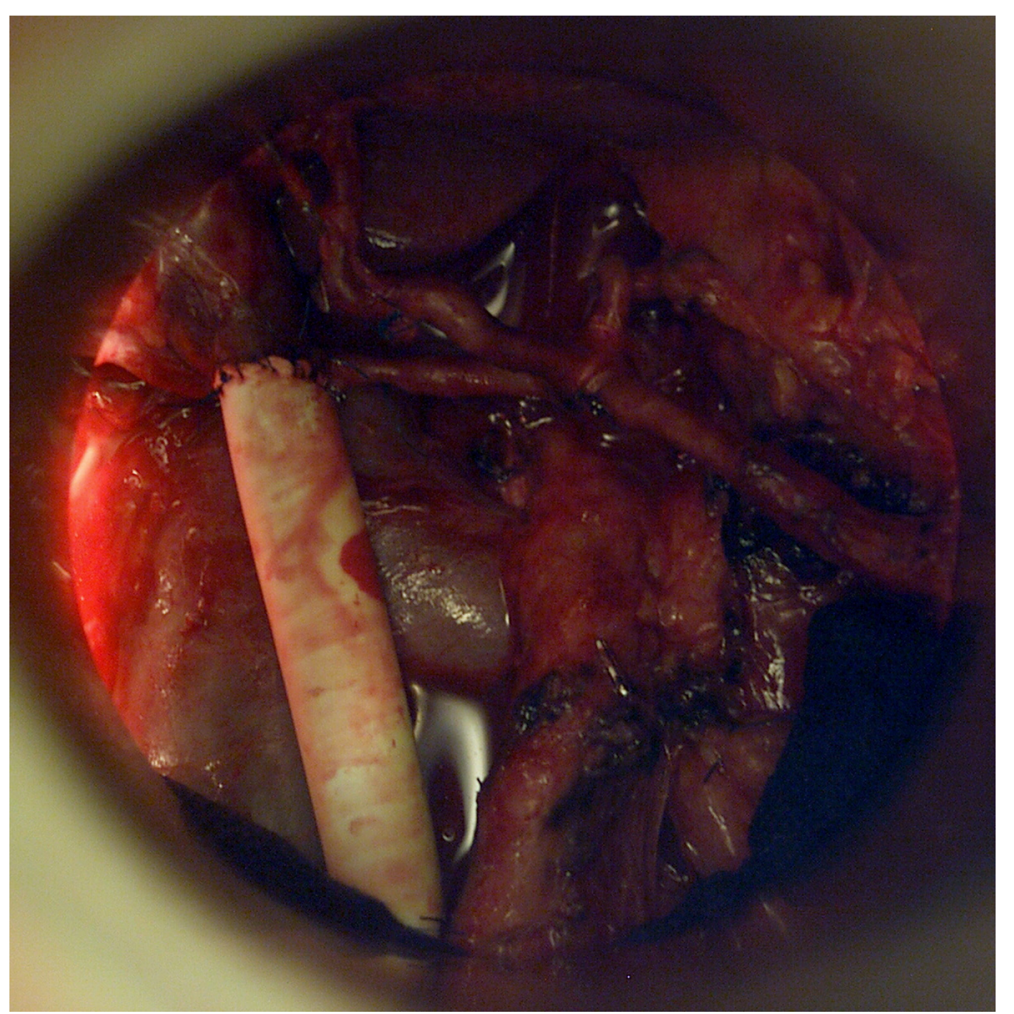

Fig. 2 Beams eye view though a intraoperative electron beam applicator to the tumor bed after resection of a locally advanced pancreatic cancer

tissues, for IORT [21, 32]. These studies created a foundation for the rational delivery of IORT in humans, so it should not be surprising that clinical studies have shown these RT doses to be safe and feasible.

\section{IORT in resectable disease}

In a prospective, randomized trial conducted at the National Cancer Institute (NCI) (Sindelar et al.) 24 patients were randomized to receive IORT (20Gy) with EBRT (satges II-IV). Excluding 7 perioperative deaths, an improvement in local control and median survival was seen in the patients who received IORT (OS 18 vs 12 month; $p=0.01$ ) [33].

All other data regarding IORT in resectable disease are limited to retrospective single- or multi-institutional series (Table 1). Of those several have evaluated outcomes in patients who have undergone resection for pancreatic cancer, comparing cohorts who received IORT versus no IORT. Nearly all of them show a benefit due to reduced locoregional recurrence by the addition of IORT around $40-80 \%$ (Table 1).

Zerbi et all reported 90 patients who underwent resection between 1985 and 1993. 43 patients received IORT in addition to surgical resection. IORT doses were between 12.5 and 20 Gy. Results revealed similar tumorsize and overall stage between both groups and no difference in operative mortality and early postoperative complications. Local recurrence in the IORT group was $27 \%$ compared to $56 \%$ in the surgery only group whereas there was no statistically significant difference in overall or disease free survival [34]. Alfieri et al. evaluated 46 patients, of which the last 26 received IORT and adjuvant EBRT. Medium survival was 10.8 month in the surgery group and 14.4 month in the surgery and IORT group $(p=0.06)$. The 5 -year local control was significantly better in the IORT group with $30 \%$ vs. $58 \%(p<0.01)$. Multivariate analysis demonstrated that IORT was an independent prognostic factor for local control [35]. Reni et al. evaluated a larger series with 127 patients receiving IORT after surgery and compared these with a cohort of 76 patients with surgery alone. As in the other studies no additional operative morbidity and mortality was observed due to the addition of IORT. In Stage I and II disease IORT significantly prolonged time to local failure, time to failure and overall survival [36]. Additional data from 2 larger multi-institutional series confirmed the favourable effect of IORT on local control [37, 38].

These studies are summarized in Table 1 and suggest an improvement in local control due to IORT without additional operative morbidity or mortality.

\section{IORT in locally advanced or unresectable disease}

In locally advanced pancreatic cancer (LAPC) the role of IORT is more clearly defined. Many studies have 
Table 1 Selected studies of Intraoperative Radiotherapy in resected pancreatic cancer

\begin{tabular}{|c|c|c|c|c|c|c|c|}
\hline Studies & Number & IORT Dose (Gy) & EBRT & $\begin{array}{l}\text { Operative } \\
\text { mortality }\end{array}$ & $\begin{array}{l}\text { Peri-/ postoperative } \\
\text { complications }\end{array}$ & Local recurrence & $\begin{array}{l}\text { Overall survival } \\
\text { (Median) }\end{array}$ \\
\hline \multirow[t]{3}{*}{ Sindelar et al. [33] } & 24 & 20 & $100 \%$ & & & & \\
\hline & 12 Surgery and EBRT & & & & & $100 \%$ & 12 month \\
\hline & $\begin{array}{l}12 \text { Surgery and IORT } \\
\text { or EBRT }\end{array}$ & & & & & $33 \%$ & 18 month \\
\hline \multirow[t]{3}{*}{ Zerbi et al. [34] } & 90 & $12.5-20$ & $36 \%$ & & & & \\
\hline & 47 Surgery & & & $2.1 \%$ & $23.4 \%$ & $56,4 \%$ & 12 month \\
\hline & 43 Surgery and IORT & & & $2.3 \%$ & $23.2 \%$ & $26 \%$ & 19 month \\
\hline \multirow[t]{3}{*}{ Alfieri et al. [35] } & 46 & 10 & $67 \%$ & & & & \\
\hline & 20 Surgery & & & $8 \%$ & $43 \%$ & 71.2 & 10.8 month \\
\hline & 26 Surgery and IORT & & & $9 \%$ & $57 \%$ & $41.6 \%$ & 14.3 month \\
\hline \multirow[t]{3}{*}{ Reni et al. [36] } & 203 & $10-25$ & $28 \%$ & & & Median time to & \\
\hline & 76 Surgery & & & $4 \%$ & $45 \%$ & local failure & 12 month \\
\hline & 127 Surgery and IORT & & & $5 \%$ & $39 \%$ & $\begin{array}{l}11 \text { month } \\
14 \text { month }\end{array}$ & 15.5 month \\
\hline \multirow[t]{2}{*}{ Ogawa et al. [37] } & 210 & $30 \%$ & $63 \%$ & & & $16.3 \%$ & 19.1 month \\
\hline & $\begin{array}{l}\text { All patients Surgery and } \\
\text { IORT }\end{array}$ & & & & & & \\
\hline Valentini et al. [38] & $\begin{array}{l}270 \\
\text { All patients surgery and } \\
\text { IORT }\end{array}$ & $7.5-25$ & $63 \%$ & & & $\begin{array}{l}\text { Median time to local } \\
\text { failure } 15 \text { month }\end{array}$ & 19 month \\
\hline \multirow[t]{3}{*}{ Showalter et al. [47] } & 99 & $10-20$ & & & & & \\
\hline & 46 Surgery + - EBRT & & $66 \%$ & & $40 \%$ & $39 \%$ & 19.2 month \\
\hline & $\begin{array}{l}37 \text { surgery IORT +- } \\
\text { EBRT }\end{array}$ & & $74 \%$ & & $46 \%$ & $21 \%$ & 21 month \\
\hline
\end{tabular}

Table 2 Selected studies of Intraoperative Radiotherapy in locally advanced/unresectable pancreatic cancer

\begin{tabular}{|c|c|c|c|c|}
\hline Studies & Number & IORT Dose (Gy) & Local Recurrence & Overall Survival (Median) \\
\hline \multirow[t]{3}{*}{ Roldan et al. [31] } & 159 & 20 & & \\
\hline & 122 EBRT & & $52 \%$ & 12.6 month \\
\hline & 37 EBRT and IORT & & $18 \%$ & 13.4 month \\
\hline Tepper et al. [39] & $\begin{array}{l}51 \\
\text { EBRT and IORT }\end{array}$ & 20 & Not assessable & 9 month \\
\hline $\begin{array}{l}\text { Willet et al. [40] } \\
\text { Cai et al. [41] }\end{array}$ & $\begin{array}{l}194 \\
\text { EBRT and IORT }\end{array}$ & $15-25$ & $\begin{array}{l}2 y \\
59 \%\end{array}$ & 12 month \\
\hline Mohiddin et al. [48] & $\begin{array}{l}49 \\
\text { EBRT and IORT }\end{array}$ & $10-20$ & $29 \%$ & 16 month \\
\hline Schuricht et al. [49] & $\begin{array}{l}105 \\
76 \text { EBRT and IORT } \\
29 \text { EBRT }\end{array}$ & $15-20$ & $30 \%$ & 15-20 month \\
\hline \multirow[t]{5}{*}{ Keane et al. [45] } & 85 (locally advanced/Borderline resectable) & $10-20$ & & \\
\hline & 26 IORT & & & 20.5 month \\
\hline & 49 resected & & & \\
\hline & 24 surgery and IORT & & & 35.1 month \\
\hline & 25 surgery & & & 301.1 month \\
\hline
\end{tabular}


documented both safety and pain control with IORT, resulting in complete pain resolution in $75-90 \%$ of cases (Table 2) [20]. Nishimura et al. were among the first to show that the addition of IORT in advanced pancreatic cancer lead to a significant improvement in pain relief compared to a control group [29]. A study from Mayo Clinic evaluated 159 patients with unresectable pancreatic cancer who underwent exploratory laparotomy. Of these 37 received EBRT in combination with IORT boost. The addition of IORT to EBRT resulted in a 1year local control of $82 \%$ compared to $48 \%$ with EBRT alone. Despite this benefit there was no difference in median or long-term survival [31].

Radiation Therapy Oncology Group (RTOG) tried to evaluate IORT in LAPC in a multi-institutional study. RTOG 8505 evaluated the role of IORT in addition to EBRT for patients with LAPC. The rate of major postoperative complications was $12 \%$ and median survival was 9 month. Local control could not adequately be evaluated in this study. This Study demonstrated the feasibility of IORT, but did not clearly show an advantage of IORT over conventional therapy [39].

Larger single institutional series have published longterm results with the use of IORT. Since 1978, patients with LAPC with good performance status have been considered for consolidative intraoperative radiotherapy (IORT) at the Massachusetts General Hospital (MGH) [4]. In 2005, Willett et al. reported that among the first 150 patients with LAPC to receive IORT at MGH as part of their treatment, the 1-year, 2-year, and 3-year overall survival (OS) rates were $54,15 \%$, and $7 \%$, respectively. It is worth noting that 5 patients survived past 5 years [40]. In an updated publications of 194 consecutive patients with unresectable LAPC comparable to previously published values were reported with 1-year, 2-year, 3-year, and 5year OS rates of $49,16,6$, and $3 \%$, respectively $[8,9]$. Multivariate analysis showed that low comorbidity index and chemotherapy predicted improved overall survival, with a median OS of 21.2 months and a 3-year OS rate of $20 \%$ in this subgroup [41].

Novel systemic treatment regimens like FOLFIRINOX and nab-paclitaxel have demonstrated improvements in prolonging survival also in advanced cases $[17,18]$. The strength of chemotherapy as a positive prognostic factor for survival in current studies supports the emphasis on upfront systemic treatment of patients with pancreatic cancer, but long-term survival is still scarce, whereas the role of radiation therapy remains controversial $[7,8]$.

The 2009 an autopsy analysis by Iacobuzio-Donahue et al. demonstrated that local tumor progression causes significant morbidity and mortality in patients with unresectable and even metastatic pancreatic cancer [42] leading again to increased attention on the role of localized treatment, i.e. localized radiotherapy.
Improved outcomes with novel chemotherapy regimes in the treatment of metastatic pancreatic cancer have prompted incorporation of these regimens into neoadjuvant treatment $[43,44]$. While some patients are still found to be unresectable after neoadjuvant treatment, others are able to undergo resection [44]. In 2016 Massachusetts General Hospital (MGH) reported retrospectively analyzed records of 85 patients with locally advanced/ borderline resectable PDAC who received neoadjuvant treatment with chemotherapy and/or chemoradiotherapy followed by surgical exploration in an IORT-equipped operating suite between 2010 and 2015 . Of 85 patients, $49(57.6 \%)$ underwent resection after neoadjuvant treatment, 27 (31.8\%) were unresectable, and $9(10.6 \%)$ were found to have distant metastases. 24 of 49 patients who underwent resection received IORT for close/positive margins on intraoperative frozen section. There was no significant difference in operative times, postoperative complications, or operative morbidity in patients who underwent resection and IORT vs those who underwent resection alone. Median OS was 31.1 months in patients who underwent resection alone and 35.1 months in patients who underwent resection and IORT. Despite the increased incidence of close/ positive margins in patients who underwent resection and IORT, the rates of local recurrence were similar to those who underwent resection alone. 26 of 27 patients with unresectable disease upon exploration received IORT. Median OS was 20.5 months [45].

These studies are summarized in Table 2. IORT in patients with unresectable pancreatic cancer show that most patients experience pain relief and improved local control.

\section{IORT in locally recurrent disease}

A retrospective study from the University of Heidelberg reported 36 patients with isolated local recurrences of pancreatic cancer who have been treated with a combination of surgery, IORT and EBRT. Median time from initial treatment to recurrence was 20 months. All patients were surgically explored. In 18 patients a gross total resection was achieved, whereas the other half received only debulking or no resection at all. All patients received IORT with a median dose of 15 Gy. Additional EBRT was applied to 31 patients with a median dose of $45 \mathrm{~Gy}$, combined with concurrent, mainly gemcitabinebased chemotherapy. Local progression was found in 6 patients after a median time of 17 months, resulting in estimated 1- and 2-year local control rates of 91 and $67 \%$, respectively. Distant failure was observed in 23 patients, mainly in liver or peritoneal space. The median estimated progression-free survival was 9 months with 1 - and 2-year rates of 40 and 26\%, respectively. They found an encouraging estimated median overall survival of 19 months, transferring into 1- and 2-year rates of 66 
and $45 \%$. Notably 6 of 36 patients (17\%) lived for more than 3 years. Severe postoperative complications were found in 3 and chemoradiation-related grade III toxicity in 6 patients. No severe IORT related toxicity was observed. Combination of surgery, IORT and EBRT in patients with isolated local recurrences of pancreatic cancer resulted in encouraging local control and overall survival with acceptable toxicity [46]. This approach seems to be superior to palliative chemotherapy or chemoradiation alone and should be considered in an otherwise difficult to treat group of patients.

\section{Conclusion}

In summary, the available data demonstrates that IORT is a safe addition to the treatment of pancreatic cancer and standard neoadjuvant or adjuvant therapies, with the intention of improving local control for patients with resectable pancreatic cancer. Series of patients with unresectable pancreatic cancer show that most patients experience pain relief and improved local control. In select studies inclusion of IORT led to improved survival. Improved outcomes with novel chemotherapy regimens led again to increased attention on the role of localized radiotherapy, since local tumor progression causes significant morbidity and mortality in patients. Intraoperative radiation therapy (IORT) techniques allow increasing the effective radiation dose and improving local tumor control. However, at present, no phase III data clearly defines the role of IORT in the management of pancreatic cancer.

\section{Acknowledgements}

Not applicable.

\section{Funding}

The authors declare that they received no funding for this review.

\section{Availability of data and materials}

Not applicable.

\section{Authors' contributions}

RK and FR drafted the manuscript. Both authors read and approved the final manuscript.

\section{Competing interests}

The authors declare that they have no competing interests.

\section{Consent for publication}

Not applicable.

\section{Ethics approval and consent to participate}

Not applicable.

\author{
Author details \\ 'Department of Radiation Oncology, Helios Clinic Berlin-Buch, \\ Schwanebecker Chaussee 50, Berlin-Buch, 13125 Berlin, Germany. \\ ${ }^{2}$ Department of Radiation Oncology, University Hospital of Munich (LMU), \\ Munich, Germany. ${ }^{3}$ Clinical Cooperation Unit Molecular Radiation Oncology, \\ German Cancer Research Center (DKFZ), Heidelberg, Germany.
}

Received: 22 July 2016 Accepted: 21 December 2016

Published online: 10 January 2017

\section{References}

1. Parkin DM, Bray FI, Devesa SS. Cancer burden in the year 2000. The global picture. Eur J Cancer. 2001;37:S4-S66.

2. Jemal A, Murray T, Ward E, Samuels A, Tiwari RC, Ghafoor A, et al. Cancer statistics, 2005. CA Cancer J Clin. 2005;55:10-30.

3. Wagner M, Redaelli C, Lietz M, Seiler CA, Friess H, Buchler MW. Curative resection is the single most important factor determining outcome in patients with pancreatic adenocarcinoma. Br J Surg. 2004;91:586-94

4. Stocken DD, Buchler MW, Dervenis C, Bassi C, Jeekel H, Klinkenbijl $\mathrm{JH}$, et al. Pancreatic Cancer Meta-analysis Group. Meta-analysis of randomised adjuvant therapy trials for pancreatic cancer. $\mathrm{Br} J$ Cancer. 2005;92:1372-81.

5. Beger HG, Rau B, Gansauge F, Poch B, Link KH. Treatment of pancreatic cancer: challenge of the facts. World J Surg. 2003;27:1075-84.

6. Tsai JY, lannitti DA, Safran H. Combined modality therapy for pancreatic cancer. Semin Oncol. 2003;30 Suppl 9:71-9.

7. Klinkenbijl JH, Jeekel J, Sahmoud T, van Pel R, Couvreur ML, Veenhof $\mathrm{CH}_{\text {, et al. }}$ Adjuvant radiotherapy and 5 -fluorouracil after curative resection of cancer of the pancreas and periampullary region: phase III trial of the EORTC gastrointestinal tract cancer cooperative group. Ann Surg. 1999;230:776-82.

8. Neoptolemos JP, Stocken DD, Friess H, Bassi C, Dunn JA, Hickey H, European Study Group for Pancreatic Cancer, et al. A randomized trial of chemoradiotherapy and chemotherapy after resection of pancreatic cancer. N Engl J Med. 2004;350:1200-10.

9. Beger HG, Poch B, Schwarz M, Ganzauge F. Pancreatic cancer: the relative importance of neoadjuvant therapy. Chirurg. 2003;74:202-7.

10. Smeenk HG, Tran TC, Erdmann J, van Eijck CH, Jeekel J. Survival after surgical management of pancreatic adenocarcinoma: does curative and radical surgery truly exist? Langenbecks Arch Surg. 2005;390:94-103.

11. Pedrazzoli S, DiCarlo V, Dionigi R, Mosca F, Pederzoli P, Pasquali C, et al. Standard versus extended lymphadenectomy associated with pancreatoduodenectomy in the surgical treatment of adenocarcinoma of the head of the pancreas: a multicenter, prospective, randomized study. Lymphadenectomy Study Group. Ann Surg. 1998;228:508-17.

12. Yeo CJ, Cameron JL, Lillemoe KD, Sohn TA, Campbell KA, Sauter PK, et al. Pancreaticoduodenectomy with or without distal gastrectomy and extended retroperitoneal lymphadenectomy for periampullary adenocarcinoma, part 2: randomized controlled trial evaluating survival, morbidity, and mortality. Ann Surg. 2002;236:355-66.

13. Demeure MJ, Doffek KM, Komorowski RA, Wilson SD. Adenocarcinoma of the pancreas: detection of occult metastases in regional lymph nodes by a polymerase chain reaction-based assay. Cancer. 1998;83:1328-34.

14. Hermanek P. Pathology and biology of pancreatic ductal adenocarcinoma. Langenbecks Arch Surg. 1998;383:116-20.

15. Kayahara M, Nagakawa T, Futagami F, Kitagawa H, Ohta T, Miyazaki I. Lymphatic flow and neural plexus invasion associated with carcinoma of the body and tail of the pancreas. Cancer. 1996;78:2485-91.

16. Hazard L, Tward JD, Szabo A, Shrieve DC. Radiation therapy is associated with improved survival in patients with pancreatic adenocarcinoma: results of a study from the Surveillance, Epidemiology, and End Results (SEER) Registry data. Cancer. 2007;110:2191.

17. Gourgou-Bourgade S, Bascoul-Mollevi C, Desseigne F, Ychou M, Bouché O, Guimbaud R, Bécouarn Y, Adenis A, Raoul JL, Boige V, Bérille J, Conroy T. Impact of FOLFIRINOX compared with gemcitabine on quality of life in patients with metastatic pancreatic cancer: results from the PRODIGE 4/ ACCORD 11 randomized trial. J Clin Oncol. 2013;31(1):23-9.

18. Von Hoff DD, Ervin T, Arena FP, Chiorean EG, Infante J, Moore M, Seay T, Tjulandin SA, Ma WW, Saleh MN, Harris M, Reni M, Dowden S, Laheru D, Bahary N, Ramanathan RK, Tabernero J, Hidalgo M, Goldstein D, Van Cutsem E, Wei X, Iglesias J, Renschler MF. Increased survival in pancreatic cancer with nab-paclitaxel plus gemcitabine. N Engl J Med. 2013;369(18):1691-703.

19. Kalser MH, Ellenberg SS. Pancreatic cancer. Adjuvant combined radiation and chemotherapy following curative resection. Arch Surg. 1985;120:899-903.

20. Crane $\mathrm{CH}$, Beddar AS, Evans DB. The role of intraoperative radiotherapy in pancreatic cancer. Surg Oncol Clin North Am. 2003;12:965-77.

21. Kinsella TJ, Sindelar WF. Intraoperative radiotherapy for pancreatic carcinoma. Experimental and clinical studies. Cancer. 1996;78(3S):598-604.

22. Palta $M$, Willett $C$, Czito $B$. The role of intraoperative radiation therapy in patients with pancreatic cancer. Semin Radiat Oncol. 2014;24(2):126-31.

23. Calvo FA, Meirino RM, Orecchia R. Intraoperative radiation therapy first part: rationale and techniques. Crit Rev Oncol Hematol. 2006;59:106-15. 
24. Kneschaurek P, Wehrmann R, Hugo C, Stepan R, Lukas P, Molls M. The flab method of intraoperative radiotherapy. Strahlenther Onkol. 1995;171:61-9.

25. Kirkpatrick JP, Meyer JJ, Marks LB. The linearquadratic model is inappropriate to model high dose per fraction effects in radiosurgery. Semin Radiat Oncol. 2008;18:240-3

26. Park C, Papiez L, Zhang S, Story M, Timmerman RD. Universal survival curve and single fraction equivalent dose: useful tools in understanding potency of ablative radiotherapy. Int J Radiat Oncol Biol Phys. 2008;70:847-52.

27. Fuks Z, Kolesnick R. Engaging the vascular component of the tumor response. Cancer Cell. 2005;8:89-91.

28. Abe M, Takahashi M. Intraoperative radiotherapy: The Japanese experience. Int J Radiat Oncol Biol Phys. 1981;7:863.

29. Nishimura Y, Hosotani R, Shibamoto Y, Kokubo M, Kanamori S, Sasai K, et al. External and intraoperative radiotherapy for resectable and unresectable pancreatic cancer: analysis of survival rates and complications. Int J Radiat Oncol Biol Phys. 1997;39:39-49.

30. Shipley WU, Wood WC, Tepper JE, et al. Intraoperative electron beam irradiation for patients with unresectable pancreatic cancinoma. Ann Surg. 1084;200:289.

31. Roldan GE, Gunderson LL, Nagorney DM, Martin JK, Ilstrup DM, Holbrook MA, Kvols LK, Mcllrath DC. External beam versus intraoperative and external beam irradiation for locally advanced pancreatic cancer. Cancer. 1988;61(6): 1110-6.

32. Sindelar WF, Kinsella TJ. Normal tissue tolerance to intraoperative radiotherapy. Surg Oncol Clin N Am. 2003;12:925-42.

33. Sindelar WF, Kinsella TJ. Studies of intraoperative radiotherapy in carcinoma of the pancreas. Ann Oncol. 1999;10(suppl4):226.

34. Zerbi A, Fossati V, Parolini D, Carlucci M, Balzano G, Bordogna G, Staudacher C, Di Carlo V. Intraoperative radiation therapy adjuvant to resection in the treatment of pancreatic cancer. Cancer. 1994;73(12):2930-5.

35. Alfieri S, Morganti AG, Di Giorgio A, et al. Improved survival and local control after intraoperative radiation therapy and postoperative radiotherapy: A multivariate analysis of 46 patients undergoing surgery for pancreatic head cancer. Arch Surg. 2001;136:343.

36. Reni M, Panucci MG, Ferreri AJM, Balzano G, Passoni P, Cattaneo GM, et al. Effect on local control and survival of electron beam intraoperative irradiation for resectable pancreatic adenocarcinoma. Int J Radiat Oncol Biol Phys. 2001;50:651-8.

37. Ogawa K, Karasawa K, Ito Y, Ogawa Y, Jingu K, Onishi H, Aoki S, Wada H, Kokubo M, Etoh H, Kazumoto T, Takayama M, Negoro Y, Nemoto K, Nishimura Y; JROSG Working Subgroup of Gastrointestinal Cancers. Intraoperative radiotherapy for resected pancreatic cancer: a multiinstitutional retrospective analysis of 210 patients. Int J Radiat Oncol Biol Phys. 2010;77(3):734-42.

38. Valentini V, Calvo F, Reni M, Krempien R, Sedlmayer F, Buchler MW, Di Carlo V, Doglietto GB, Fastner G, Garcia-Sabrido JL, Mattiucci G, Morganti AG, Passoni P, Roeder F, D'Agostino GR. Intra-operative radiotherapy (IORT) in pancreatic cancer: joint analysis of the ISIORT-Europe experience. Radiother Oncol. 2009;91(1):54-9.

39. Tepper JE, Noyes D, Krall JM, Sause WT, Wolkov HB, Dobelbower RR, Thomson J, Owens J, Hanks GE. Intraoperative radiation therapy of pancreatic carcinoma: a report of RTOG-8505. Radiation Therapy Oncology Group. Int J Radiat Oncol Biol Phys. 1991;21(5):1145-9.

40. Willett CG, Del Castillo CF, Shih HA, Goldberg S, Biggs P, Clark JW, Lauwers G, Ryan DP, Zhu AX, Warshaw AL. Long-term results of intraoperative electron beam irradiation (IOERT) for patients with unresectable pancreatic cancer. Ann Surg. 2005;241(2):295-9.

41. Cai S, Hong TS, Goldberg SI, Fernandez-del Castillo C, Thayer SP, Ferrone CR, Ryan DP, Blaszkowsky LS, Kwak EL, Willett CG, Lillemoe KD, Warshaw AL, Wo JY. Updated long-term outcomes and prognostic factors for patients with unresectable locally advanced pancreatic cancer treated with intraoperative radiotherapy at the Massachusetts General Hospital, 1978 to 2010. Cancer. 2013;119(23):4196-204.

42. lacobuzio-Donahue CA, Fu B, Yachida S, Luo M, Abe H, Henderson CM, Vilardell F, Wang Z, Keller JW, Banerjee P, Herman JM, Cameron JL, Yeo CJ, Halushka MK, Eshleman JR, Raben M, Klein AP, Hruban RH, Hidalgo M, Laheru D. DPC4 gene status of the primary carcinoma correlates with patterns of failure in patients with pancreatic cancer. J Clin Oncol. 2009; 27(11):1806-13.

43. Conroy T, Bachet JB, Ayav A, Huguet F, Lambert A, Caramella C, Maréchal R, Van Laethem JL, Ducreux M. Current standards and new innovative approaches for treatment of pancreatic cancer. Eur J Cancer. 2016;57:10-22.
44. Hackert T, Sachsenmaier M, Hinz U, Schneider L, Michalski CW, Springfeld C, Strobel O, Jäger D, Ulrich A, Büchler MW. Locally Advanced Pancreatic Cancer: Neoadjuvant Therapy With Folfirinox Results in Resectability in 60\% of the Patients. Ann Surg. 2016 [Epub ahead of print].

45. Keane FK, Jennifer Yon-Li W, Cristina F, Clark JW, Lawrence Scott B, Allen JN, Eunice Lee K, Ryan DP, Lillemoe KD, Carlos Fernandez-del C, Theodore S, Hong J. Intraoperative radiotherapy (IORT) in the era of intensive neoadjuvant chemotherapy and chemoradiotherapy for locally advanced and borderline resectable adenocarcinoma of the pancreas (PDAC). Clin Oncol. 2016;34(suppl 4S):abstr 393.

46. Roeder F, Timke C, Uhl M, Habl G, Hensley FW, Buechler MW, Krempien R, Huber PE, Debus J, Werner J. Aggressive local treatment containing intraoperative radiation therapy (IORT) for patients with isolated local recurrences of pancreatic cancer: a retrospective analysis. BMC Cancer. 2012 12:295.

47. Showalter TN, Rao AS, Rani Anne P, Rosato FE, Rosato EL, Andrel J, Hyslop T, Xu X, Berger AC. Does intraoperative radiation therapy improve local tumor control in patients undergoing pancreaticoduodenectomy for pancreatic adenocarcinoma? A propensity score analysis. Ann Surg Oncol. 2009;16(8):2116-22.

48. Mohiuddin M, Regine WF, Stevens J, Rosato F, Barbot D, Biermann W, et al. Combined intraoperative radiation and perioperative chemotherapy for unresectable cancers of the pancreas. J Clin Oncol. 1995:13:2764-8.

49. Schuricht AL, Spitz F, Barbot D, Rosato F. Intraoperative radiotherapy in the combined-modality management of pancreatic cancer. Am Surg. 1998; 64(11):1043-9.

\section{Submit your next manuscript to BioMed Central and we will help you at every step:}

- We accept pre-submission inquiries

- Our selector tool helps you to find the most relevant journal

- We provide round the clock customer support

- Convenient online submission

- Thorough peer review

- Inclusion in PubMed and all major indexing services

- Maximum visibility for your research

Submit your manuscript at www.biomedcentral.com/submit

) Biomed Central 